\title{
Decision Trees for Sense Disambiguation of Prepositions:
}

\author{
Case of Over
}

\author{
Yukiko Sasaki Alam \\ Dept. of Digital Media Science \\ Hosei University, Tokyo \\ sasaki@k.hosei.ac.jp
}

\begin{abstract}
This paper proposes two decision trees for determining the meanings of the prepositional uses of over by using the contextual information. It first examines the meanings of the prepositional uses of over and then aims at identifying the contexts for interpreting the meanings. Some contexts are complementary features, and that makes the decision trees simple. The trees have been tested on a corpus, and the results are encouraging.
\end{abstract}

\section{Introduction}

Prepositions have been studied from a variety of perspectives. The syntactic status has been probed by such linguists as Jackendoff [77], Emonds [85], Rauh [93] and Pullum and Huddleston [02]. Cognitive theorists have paid attention to the polysemous nature of prepositions and explored the conceptual relationships of the polysemy, often proposing the graphical mental images (Lakoff and Johnson [80], Brugman [81, 88], Herskovits [86], Langacker [87], Tyler and Evans [01]). Pragmatic aspects of prepositions have been studied by such scholars as Fauconnier [94] and Visetti and Cadiot [02]. The deictic properties of spatial prepositions have been examined by Hill [82], while the geographical information provided by them was an interest of computational research (Xu and Badler [00], Tezuka et al [01]). A practical study of the usage of prepositions was carried out for the purpose of teaching English as a second language (Wahlen [95], Lindstromberg [97], Yates [99]). In the fields related to natural language processing, prepositional phrase attachment has been a topic for research for quite a long time, and in recent years, the problem was explored with a neural network-based approach (Sopena, LLoberas and Moliner [98]) and with a syntax-based trainable approach (Yeh and Valin [98]). Although past research has revealed various aspects of prepositions, to my knowledge there is not much semantic research of prepositions available for computational use, which requires a vigorous formalization of representing the semantics.

A recent semantic study of prepositions for computational use is found in Voss [02], with a focus on spatial prepositions. Spatial prepositions are divided into three categories according to which one of the two thematic meanings between place and path they acquire when they are in argument, adjunct and non-subcategorized positions of particular types of verbs. The semantics of spatial prepositions dealt with in Voss [02] is not lexical but thematic.

The present study places more focus on the lexical meanings of prepositions rather than on the thematic meanings because it is intended for use in machine translation (MT), where the meaning of a sentence, a phrase or a lexical entry of a source language must be preserved in the target language, even though it may take a different syntactic form in the source and target languages. The preservation of meaning is even more important at an Interlingua-based MT, because meaning is a medium of translation between source and target languages.

The current research deals with the prepositional uses of over, but not with the uses of over in different syntactic categories such as the use as adjective (as in The initial test is over), as part of a phrasal verb (as in He handed over his notes to me), as part of an idiomatic phrase (as in She said it over and over) and as a modifier of a quantity (as in over forty years ago). These uses could be identified in terms of their syntactic characteristics. On the other hand, the prepositional uses are grouped under the same syntactic category, but exhibit different meanings in different semantic contexts, requiring semantic treatments as well for the disambiguation of the senses. 
This paper examines the meanings of the prepositional uses of over, identifies the semantic contexts, and proposes two decision trees for interpreting the different meanings. The second section will divide the prepositional uses of over into two groups according to which one of the two functional units between Head and Complement is likely to identity the meanings. It will also bring into light the semantic features of the Head and Complement components that make the interpretations of the uses possible. The third section will discusses the two decision trees proposed in this paper, and the fourth section gives an evaluation of the trees, before concluding this paper.

\section{Meanings of the prepositional uses}

Prepositional uses of over could be divided into two groups: those whose meaning is likely to be identified by the Complement noun phrases and those that need semantic information in the Head components. The noun phrase following a preposition is the Complement of the preposition, whereas the verb, verb phrase, noun or noun phrase governing a preposition or a prepositional phrase is the Head.

\subsection{Over identified by its Complement}

Unlike the uses of over governed or required by the Head verb or noun, over the weekend in They have been unwell over the weekend can appear with almost all semantic classes of verbs, as illustrated below.

(1) a. I heard over the weekend of a terrible fuss.

b. He thought about it over the weekend and accepted.

c. Talks with bankers were taking place over the weekend.

d. It probably began over the weekend of March 27.

e. His father had died over the weekend.

f. American diplomats arrived here over the weekend.

The phrase over the weekend appears with a sensation verb (1a), a cognition verb (1b), an occurrence verb (1c), an aspectual verb (1d), a change of state verb (1e) and a movement verb (1f). This suggests that over the weekend is not required by a particular semantic class of verbs. At the same time, it is likely to be identified from the semantic features of the Complement noun phrase, which denotes a definite period of time in discourse during which an event takes place. This use of over is called over_during because it is similar to the usage of during.

On the other hand, over can appear with the Complement denoting an indefinite period of time in discourse, as in:

(2) Altogether, tutorials take place over a period of about twenty-four weeks.
The Complements of over_during in (1) and this use share the semantic characteristic by referring to time of duration, but differ in that the former refers to a specific period of time in discourse while the latter only a length of time over which an event continues. This use is named over_duration.

Another use that denotes a length of time is as follows:

(3) Skimming a chapter for its main ideas may be done over coffee.

Unlike the other two we have seen above, the Complement does not refer directly to a space of time, but still the prepositional phrase implies an interval of time, in particular the duration of drinking coffee. Like the use of over_duration, the Complement does not refer to a definite period in discourse because the semantic function is to indicate a length of time. The Complement in this type is characterized by its meaning denoting meal or drink as well as by referring to a nonspecific meal or drink in discourse. This use is termed over_coffee.

Like the three uses we have seen above, the following is also likely to be identified by the syntax and semantics of the Complements:

(4) We heard the news over the radio at lunch break.

The phrase over the radio indicates a means of hearing the news. The Complement in this use is often a sequence of the definite particle the followed by a noun denoting a device of communication such as radio and telephone. Although the Head verb or noun tends to refer to a communicative act, as this use takes a Complement with distinctive semantic features, it should belong to this group. It is called over_means.

Another use of over that could belong to this group is the following:

(5) You can go all over the place.

The Complement denotes a place in many cases, but sometimes a physical object, and this use of over is always preceded by all. Although the Head verb or noun tends to denote movement, this use also appears with other types of predicates, as illustrated below:

(6) a. Paint all over the studio.

b. He is known all over Europe.

c. Tapes crash all over my desk.

The following is a list of the prepositional uses of over that are likely to be identified by the semantic features of the Complements: 


\begin{tabular}{|l|l|}
\hline meanings & \multicolumn{1}{|c|}{ examples } \\
\hline over_during & $\begin{array}{l}\text { Over the next decade a global } \\
\text { approach is going to be essen- } \\
\text { tial. }\end{array}$ \\
\hline $\begin{array}{l}\text { over__ } \\
\text { duration }\end{array}$ & $\begin{array}{l}\text { Their flowers appear over sev- } \\
\text { eral weeks in summer. }\end{array}$ \\
\hline over_coffee & $\begin{array}{l}\text { There's a lot for you to talk } \\
\text { about over lunch. }\end{array}$ \\
\hline over_means & $\begin{array}{l}\text { Lewd songs are sung over the } \\
\text { microphone. }\end{array}$ \\
\hline $\begin{array}{c}\text { over_many- } \\
\text { parts }\end{array}$ & $\begin{array}{l}\text { The dog ran all over the parking } \\
\text { lot. }\end{array}$ \\
\hline
\end{tabular}

Table 1. Uses identifiable by the Complements

The following is a list of the features identifying the uses of over by the Complements.

\begin{tabular}{|l|l|l|}
\hline meanings & $\begin{array}{l}\text { features of } \\
\text { the Heads }\end{array}$ & \multicolumn{1}{|c|}{$\begin{array}{c}\text { features of the Com- } \\
\text { plements }\end{array}$} \\
\hline $\begin{array}{l}\text { over_ } \\
\text { during }\end{array}$ & & $\begin{array}{l}\text { time } \\
\text { +definite, +duration, }\end{array}$ \\
\hline $\begin{array}{l}\text { over_ } \\
\text { duration }\end{array}$ & & $\begin{array}{l}\text { time } \\
\text {-definite, +duration }\end{array}$ \\
\hline $\begin{array}{l}\text { over_ } \\
\text { coffee }\end{array}$ & $\begin{array}{l}\text { \{meal, drink\} } \\
\text {-definite }\end{array}$ \\
\hline $\begin{array}{l}\text { over_ } \\
\text { means }\end{array}$ & $\begin{array}{l}\text { communication tool, } \\
\text { +definite }\end{array}$ \\
\hline $\begin{array}{l}\text { over_ } \\
\text { many- } \\
\text { parts }\end{array}$ & $\begin{array}{l}\text { \{place, physical object } \\
\text { [syntactic features: all } \\
\text { over + NP] }\end{array}$ \\
\hline
\end{tabular}

Table 2. The features of the Complements distinguishing the meanings of over

\subsection{Over identifiable by its Head}

Unlike the prepositional uses of over that are likely to be identified by the semantics of the Complements alone, the following are the uses that would require the semantic information of the Heads as well for identification.

\subsubsection{Head denoting a physical event}

When the Head of over denotes movement and the Complement a place or a physical object, the overprepositional phrase indicates a place above which and across which an object moves, as given below:

(7) a. The bullet goes flying over my head and lands in the field behind me.

b. Safe, efficient movement over snow and ice is impossible without suitable crampons.
The prepositional phrase indicates a path over which an object moves, and therefore it is termed over_path.

Another use of over indicating place is illustrated by the following example:

(8) After spreading her napkin over her lap,

Alice began to eat.

The prepositional phrase implies a place on which or above which an object sits. In this example, her napkin is placed over her lap. This use is called over_locus. The Head refers to an event denoted by a verb or noun belonging to the put verb class (cf. Levin [93]) while the Complement a place or a physical object.

In addition, this use is also used with a Head verb denoting the presence of an object as in:

(9) An occasional loop stays over the needle after knitting the row.

Indeed, this use is more complex than it appears. In a sentence with the BE verb, we find the following examples:

(10) a. My painting is over the sofa.

b. There were no taps over the sink.

The use of over in this construction is tricky because it is difficult to distinguish from the use of over meaning about, as illustrated below:

(11) The disagreement here is over the substitutability of assets.

As complex as such, this construction would need a special syntactic treatment separately from other uses. That is, in this construction, the subject noun phrase is the Head of over, and thus the semantics of the subject along with that of the Complement must be examined for proper identification.

Another special syntactic treatment should be given to an over-prepositional phrase modifying a noun phrase or noun, as in:

(12) I can just see the light over the door from where I'm standing.

In this example, the Head is a noun phrase the light and the Complement the door. Since the Head is a physical object, and the Complement a physical object, the use of over is over_locus, which means that the Head entity is located at the Complement entity. When the Head in this nominal modifier construction denotes an event or state, as in his return flight over the North Sea, there would be no special treatment required. It can be treated in the same manner as when the verb is the Head.

A special pragmatic knowledge should come into play in the use of over_locus. It is not straight-forward, in fact, to determine this use only by the semantics of the Head and Complement. In every construction for this use, there is a possibility that the prepositional phrase indicates the meaning of across, as illustrated in:

(13) a. His apartment is over my flat.

b. His apartment is over the river.

Although both sentences have the same syntactic structure, they have noun phrases referring to different places. 
As an apartment can be located over a flat in the real world, the meaning of the prepositional phrase in (13a) implies a place where an object is located (i.e. over_locus). On the other hand, as an apartment is usually not located above the river, the meaning in (13b) implies a place across where an object is situated. This latter use of over is named over_across. To distinguish between over_locus and over_across requires more than the semantics of the Head and Complement components. The distinction would require encyclopedic world knowledge. Without having such a knowledge system, this paper will treat both over_locus and over_across in the same manner except for the fact that the default choice between the two is over_locus due to the much higher frequency in its use.

\subsubsection{Head denoting a nonphysical event}

There are four uses of over whose Head denotes a nonphysical event. The use we examine at first is illustrated in the following examples:

(14) a. Marcos ruled over the Philippines for 20 years.

b. He has considerable control over her activities.

c. He had one huge advantage over everyone else.

The Head denotes an act of control or having more power. Among verbs of such a class are preside, rule, win, excel, dominate and tower. This use metaphorically implies that an object is above the other object in terms of power.

The next use of over is found in:

(15) A general dictionary was preferred over the domain-specific dictionaries.

The Head is a verb or noun denoting selection. Among them are prefer, choose, select, favor and the deverbal nouns. This use is called over_prefer. The noun counterpart of a verb in this class, however, should be treated with care, because the over may imply the meaning of about, as in

(16) They are organized to allow the users choice over what to see, in the correct time sequence.

What is going on is that over_prefer requires two entities in order to choose one over the other. When there are no such two entities between which to choose, as in (16), the meaning of over turns out to be that of about. On the other hand, when there are, the meaning is over_prefer, as illustrated in:

(17) One of the most basic freedoms anywhere is the right to peace, and the choice of quiet over noise.

Since verbs of this family are transitive verbs requiring the Object, when the sentence contains both the Object noun phrase and an over-prepositional phrase, the mean- ing of over_prefer obtains. In the proposed decision tree involving this use, the Head is limited to a verb, not a noun because of this syntactic freedom of a noun in this category. (To handle cases involving such a noun, a question as to the number of the arguments governed by the noun must be added.)

A final discussion is about two uses named over_about and over_because. The use of over_because is illustrated in the following examples:

(18) a. Teachers were suspended over war posters.

b. He quit over a bribery scandal.

The over-prepositional phrase implies a cause of the event or state. It seems that the meaning of over_because requires a punctual event as in (18a) and (18b). On the other hand, over with durational verbs in this class gives rise to the meaning of over_about, as illustrated by the following examples:

(19) a. He talked over the issue for three hours.

b. Disputes over authorship are fiercely fought.

c. There is growing concern over his illness.

d. They thought over all the possible errors.

The Head of this use denotes events of communication (such as hear and chat), agree events (such as disagree and fight), psychological events or states (such as worry, cry and agonize) and cognitive events or states (such as think and know).

Table 3 shows the uses of over the meanings of which are identified mainly by the semantics of the Head.

\begin{tabular}{|l|l|}
\hline \multicolumn{1}{|c|}{ meanings } & \multicolumn{1}{|c|}{ examples } \\
\hline over_path & Let the eye move over it. \\
\hline over_across & $\begin{array}{l}\text { The gallery is over the front door. } \\
\text { I admit that part of the ball was over } \\
\text { the line, but that's not enough. }\end{array}$ \\
\hline over_locus & Jessica sprayed paint over the furniture. \\
\hline over_control & $\begin{array}{l}\text { It was Prime Minister Yoshida who } \\
\text { presided over Japan's post-war eco- } \\
\text { nomic boom. }\end{array}$ \\
\hline over_prefer & I would prefer coffee over tea. \\
\hline over_about & $\begin{array}{l}\text { He’s mulling over an offer from NBC } \\
\text { to star in his own series. } \\
\text { At the counter, a couple puzzled over } \\
\text { which lottery numbers to choose. }\end{array}$ \\
\hline $\begin{array}{l}\text { over_ } \\
\text { because }\end{array}$ & $\begin{array}{l}\text { peachers were suspended over war } \\
\text { He quit over a bribery scandal. }\end{array}$ \\
\hline
\end{tabular}

Table 3. The meanings of over identified by its Head

Table 4 lists the semantic features in the Head that contribute to identifying the meanings of the prepositional uses of over. 


\begin{tabular}{|c|c|c|}
\hline meanings & $\begin{array}{l}\text { features of the- } \\
\text { Heads }\end{array}$ & $\begin{array}{l}\text { features of the } \\
\text { Complements }\end{array}$ \\
\hline $\begin{array}{l}\text { over__ } \\
\text { path }\end{array}$ & move events & $\begin{array}{l}\text { \{place, physi- } \\
\text { cal object }\end{array}$ \\
\hline $\begin{array}{l}\text { over_- } \\
\text { locus }\end{array}$ & $\begin{array}{l}\text { put events, stay } \\
\text { events, be verb }\end{array}$ & $\begin{array}{l}\text { \{place, physi- } \\
\text { cal object }\end{array}$ \\
\hline $\begin{array}{l}\text { over_- } \\
\text { across }\end{array}$ & $\begin{array}{l}\text { put events, stay } \\
\text { events, be verb }\end{array}$ & $\begin{array}{l}\text { \{place, physi- } \\
\text { cal object }\end{array}$ \\
\hline $\begin{array}{l}\text { over__ } \\
\text { control }\end{array}$ & control events & \\
\hline $\begin{array}{l}\text { over_- } \\
\text { prefer }\end{array}$ & prefer verbs & \\
\hline $\begin{array}{l}\text { over__ } \\
\text { about }\end{array}$ & $\begin{array}{l}\text { +duration } \\
\text { communication } \\
\text { events, agree } \\
\text { events, psychologi- } \\
\text { cal events/states, } \\
\text { cognitive } \\
\text { events/states, }\end{array}$ & \\
\hline $\begin{array}{l}\text { over__ } \\
\text { because }\end{array}$ & $\begin{array}{l}\text {-duration } \\
\text { psychological } \\
\text { events/states, } \\
\text { cognitive } \\
\text { events/states }\end{array}$ & \\
\hline
\end{tabular}

Table 4. Semantic features in the Head identifying the meanings of over

\section{Decision Trees for Disambiguation}

How do we distinguish computationally the meanings of the prepositional uses of over listed in Tables 1 and 3? Based on Tables 2 and 4, which are lists of the semantic features in the Complements and Heads that are likely to identify the meanings of over, two decision trees are proposed. One is used to identify the meanings of over from the semantic features of the Complements (Figure 1 in the Appendix), and the other, from the semantic features of the Heads (Figure 2 in the Appendix). The first search for the meaning of over should start with the decision tree by its Complement (illustrated in Figure 1), because most prepositional uses of over characterized by the Complements denote time over event, and that means that they are the modifiers of events (at the level of verb phrases) rather than the modifiers of individual verbs (located inside verb phrases). After failing in the initial search at the decision tree by its Complement, another search for the meaning of over should take place at the decision tree by its Head in Figure 2.

The decision tree in Figure 1 asks whether the Complement of over refers and/or contains such features as listed in the diamonds, while in the decision tree in Figure 2, the question concerns the Head of over.

The Head component of over can be a verb governing the over-prepositional phrase (as in I would
PREFER coffee over tea), a verb phrase modified by the over-prepositional phrase (as in A BIG EARTHQUAKE OCCURED over the weekend) or a noun (as in He has considerable CONTROL over her activities). In the BE verb construction (such as The issue is over the election of the chairman), the subject is the Head of over. The Complement of over is a noun phrase governed by over (as in over THE SPRING BREAK).

\section{Evaluation}

An evaluation of the two decision trees was conducted manually by using 500 sentences containing over produced by the British National Corpus (BNC). Among the 500 instances of over, there are 382 prepositional uses. Among the remaining, fifty six (56) instances are those meaning more than or excess, which are located characteristically immediately before a quantity word or phrase. Examples are given below:

(20) (a) We have visited over 90 schools and reached 36,000 pupils.

(b) Anything over this amount is, basically liable to inheritance tax at $40 \%$.

Twenty (20) instances of over are adjectives meaning completion, as in:

(21) My war seemed to be over.

Fifteen (15) instances are those used as adverb, an example of which is illustrated:

(22) ..., and read the list over and over again.

The sentences including over and over again are repeated twice in the data because of the two instances of over in the phrase. The data contains six such sentences, resulting in 12 counts of over and over again. Seven (7) instances are used right before the to-prepositional phrase or toward-prepositional phrase, as in:

(23) She went over to the Cookery and Refreshments Tent, but ...

The distinction between such instances of over as in (21), (22) and (23) on one hand and prepositional uses on the other could be made by purely syntactic treatments because of their different syntactic characteristics. Most of instances meaning more than or excess as illustrated in (20) are morphologically distinguishable from prepositional uses, because most of quantity nouns or noun phrases after over refer to something other than time. However, among the total 56 instances implying more than or excess, thirteen (13) quantity phrases refer to time. As such a phrase is composed of the same structure (over + noun/noun phrase) as an over-prepositional phrase, this appears to cause difficulty. But a careful examination of these constructions reveals otherwise. Such a phrase of quantity occurs in a syntactic position requiring a noun phrase, as illustrated in:

(24) a. ... after 12 years of living in those conditions, I would probably want to die myself. 


$$
\begin{aligned}
& \text { b. ... I had heard nothing about my } \\
& \text { family for over ten years. } \\
& \text { c. ... since they were written over } 10 \\
& \text { years ago, ... }
\end{aligned}
$$

All these phrases of quantity are located either after a preposition such as for, in, within and after or in an adverbial phrase ending with such a word as ago and late. Therefore, a good syntactic parser should be capable of distinguishing these quantity phrases with over from over-prepositional phrases.

Two instances of over are found in quoted phrases in sentences. Eighteen (18) sentences are either incomplete (as in PUB REFURBISHMENTS - OVER THE LIMIT and Over the wrenched?) or difficult to parse (as in First part over, second part starts and ... moved hard over in the direction of the spin).

With the non-prepositional uses and anomalous instances of over in the data aside, the next topic of discussion is about the three hundred and eighty two (382) prepositional uses found in the data. Among the 382, eighty seven (87) instances of over are parts of phrasal verbs or idiomatic phrases. Among the 87, fifty (50) instances of over do NOT govern a prepositional phrase, as illustrated below:

(25) a. And Dicky can take over as a footman.

b. She went over to fetch a cup of coffee.

c. I explain the position to the daughters and hand Mum over to them.

d. ... there is no reason for their practiced eyes to cloud over when ...

Thirty seven (37) instances of over are parts of phrasal verbs governing an over-prepositional phrase. Examples are given below:

(26) a. Go over the launch failure procedures after any long lay-off from flying.

b. .... and failed promptly to hand over detainees to the police - ...

With the lexicon containing sufficient information on such phrasal verbs, there would remain two hundred and ninety five (295) prepositional uses of over, the meanings of which must be distinguished. The decision trees proposed in this paper succeeded in determining the meanings of two hundred and seventy six (276) instances, and failed to interpret the meanings of nineteen (19), resulting in a precision of 93.5 percent. However, if the system does not recognize phrasal verbs, the value of the precision will be lower.

Some more problems and possible solutions are discussed here. It would be difficult to determine the use of over when the verbs in the sentence are conjoined, as in We finished our coffee and watched the seagulls whirling and shrieking over the harbour in the spring sunshine. When the verb shriek is categorized as a psychological verb, the use of over will be interpreted as over_about, which is a wrong interpretation in this case.
The decision tree in Figure 1 will fail to recognize the following example because a search for the use of over_means requires the semantic feature +definite: ... the cruel, brutal voices that bellow over loudhailers about injustice .... The Complement of over, loudhailers is not preceded by the definite article the, which is a requirement for identifying over_means. The feature +definite may be dispensable for sense identification, but it will be needed when the decision tree is used for generation, because the definite article often occurs in this type of prepositional phrase as in over the phone.

A difficulty in determining whether a noun refers to a physical object or an abstract entity causes a problem. The example ... with the lying motto over its gate ... is hard to analyze. The use in this example is not over_about, but over_locus. With the correct interpretation of motto either as a physical object or a statement, the decision tree could lead to the right meaning of over. If motto refers to a physical object, the use of over is over_locus, whereas if it is not, the use is over_about.

In the example such as The drag of the cable over one wing can make ..., the deverbal noun drag must be properly parsed as the Head of over in order to interpret the meaning of over correctly.

Based on the assumption (a) that a syntactic parsing is successful, (b) that the over in phrasal verbs are recognized beforehand, and (c) that verbs and nouns are properly categorized into classes, the two decision trees could identify the meanings of most prepositional uses of over in the corpus. In addition, information on whether the Head event refers to a durational event or not would enable the tree to distinguish between over_about and over_because. Table 5 gives a breakdown of the instances of over found in the data (PP stands for prepositional phrase):

\begin{tabular}{|l|l|}
\hline over included in or used as & No. \\
\hline PP (over not in phrasal verbs) & $\begin{array}{l}295 \\
(19 \\
\text { failed) }\end{array}$ \\
\hline PP (over in phrasal verbs) & 37 \\
\hline $\begin{array}{l}\text { parts of phrasal verbs (not } \\
\text { governing PP) }\end{array}$ & 50 \\
\hline quantity modifier & 56 \\
\hline adjective, meaning completion & 20 \\
\hline adverb (all over again, etc.) & 15 \\
\hline $\begin{array}{l}\text { over followed by a directional } \\
\text { PP (over other than parts of } \\
\text { phrasal verbs) }\end{array}$ & 7 \\
\hline inside quotes & 2 \\
\hline unable to parse & 18 \\
\hline
\end{tabular}

Table 5. Breakdown of over in 500 instances 


\section{Conclusion}

After examining the meanings, the prepositional uses of over have been divided into two groups: those whose meanings are identifiable by their Complements and those by their Heads. Previous studies have focused on the identification of the meanings of over, whereas the present paper not only on the meanings, but on the contexts for interpreting the meanings.

Two decision trees have been proposed for determining the meanings of the prepositional uses of over by using the semantic features of the Head and Complement components. The decision trees are fairly simple and easy to implement in a system. The decision trees have been successful in identifying the meanings of the prepositional uses of over in data taken from BNC.

\section{References}

Brugman, Claudia. 1988. The story of over: Polysemy, semantics and the structure of the lexicon. New York: Garland Press. [1981. The story of over. Berkely, CA: UC-Berkely MA thesis.]

Emonds, Joseph. 1985. A unified theory of syntactic categories. Dordrecht: Foris.

Fauconnier, Gilles. 1994. Mental spaces. Cambridge: Cambridge University Press.

Feigenbaum, Susanne and Dennis Kurzon (eds.). 2002. Prepositions in their syntactic, semantic and pragmatic context. Amsterdam: John Benjamins.

Herskovits, Annette. 1986. Language and spatial cognition An interdisciplinary study of the prepositions in English. Cambridge: Cambridge University Press.

Hill, Cliffort 1982. Up/down, front/back, left/right. A contrastive study of Hausa and English. In Weissenborn and Klein, 13-42.

Huddleston, Rodney and Geoffrey Pullum. 2002. The Cambridge grammar of the English language. Cambridge: Cambridge University Press.

Jackendoff, Ray. 1977. The architecture of the language. Cambridge, MA: MIT Press.

Jacobs, Roderick and Peter Rosenbaum. 1970. Readings in English Transformational Grammar. Waltham, Mass.: Ginn \& Company.

Lakoff, George and Mark Johnson. 1980. Metaphors we live by. Chicago: University of Chicago Press.

Langacker, Ronald. 1987. Foundations of cognitive grammar, vol. 1. Stanford, CA: Stanford University Press.
Levin, Beth. 1993. English verb classes and alternations. Chicago/London: The University of Chicago Press.

Lindstromberg, Seth. 1998. English prepositions explained. Amsterdam: John Benjamins.

Pullum, Geoffrey and Rodney Huddleston. 2002. Prepositions and prepositional phrases. In Huddleston and Pullum (eds.), 597-661.

Rauh, Gisa. 1993. On the grammar of lexical and nonlexical prepositions in English. In Zelinskiy-Wibbelt (eds.), 99-150.

Sopena, Joseph M., Agusti LLoberas and Joan L. Moliner. 1998. A connectionist approach to prepositional phrase attachment for real world texts. In COLING-ACL '98, 1233-1237.

Tezuka, Taro, Ryong Lee, Yahiko Kambayashi and Hiroki Takakura. 2001. Web-based inference rules for processing conceptual geographical relationships. Proceedings of Web Information Systems Engineering, 14-21.

Tyler, Andrea and Vyvyan Evans. 2001. Reconsidering prepositional polysemy networks: The case of over. Language 77.724-765.

Visetti, Yves-Marie and Pierre Cadiot. 2002. Instability and the theory of semantic forms Starting from the case of prepositions. In Feigenbaum, Susanne and Dennis Kurzon (eds.), 9-39.

Voss, Clare. 2002. Interlingua-based machine translation of spatial expressions. University of Maryland: Ph.D. Dissertation.

Wahlen, Gloria. 1995. Prepositions illustrated. Michigan: The University of Michigan Press.

Weissenborn, Juergen and Wolfgang Klein. 1982. Here and there. Cross-linguistic studies on deixis and demonstration. Amsterdam/Philadelphia: Benjamins.

Xu, Yilun Dianna and Norman Badler. 2000. Algorithms for generating motion trajectories described by prepositions. Proceedings of Computer Animation 2000, 30-35.

Yates, Jean. 1999. The ins and outs of prepositions A guidebook for ESL students. New York: Barron's.

Yeh, Alexander S. and Marc B. Vilain. 1998. Some properties of preposition and subordinate conjunction attachments. In COLING-ACL '98, 1436-1442.

Zelinsky-Wibbelt, Cornelia (ed.). 1993. The semantics of prepositions: From mental processing to natural language processing. Berlin: Mouton de Gruyter. 


\section{Appendix}

DOES THE COMPLEMENT REFER TO AND/OR CONTAIN ... ?

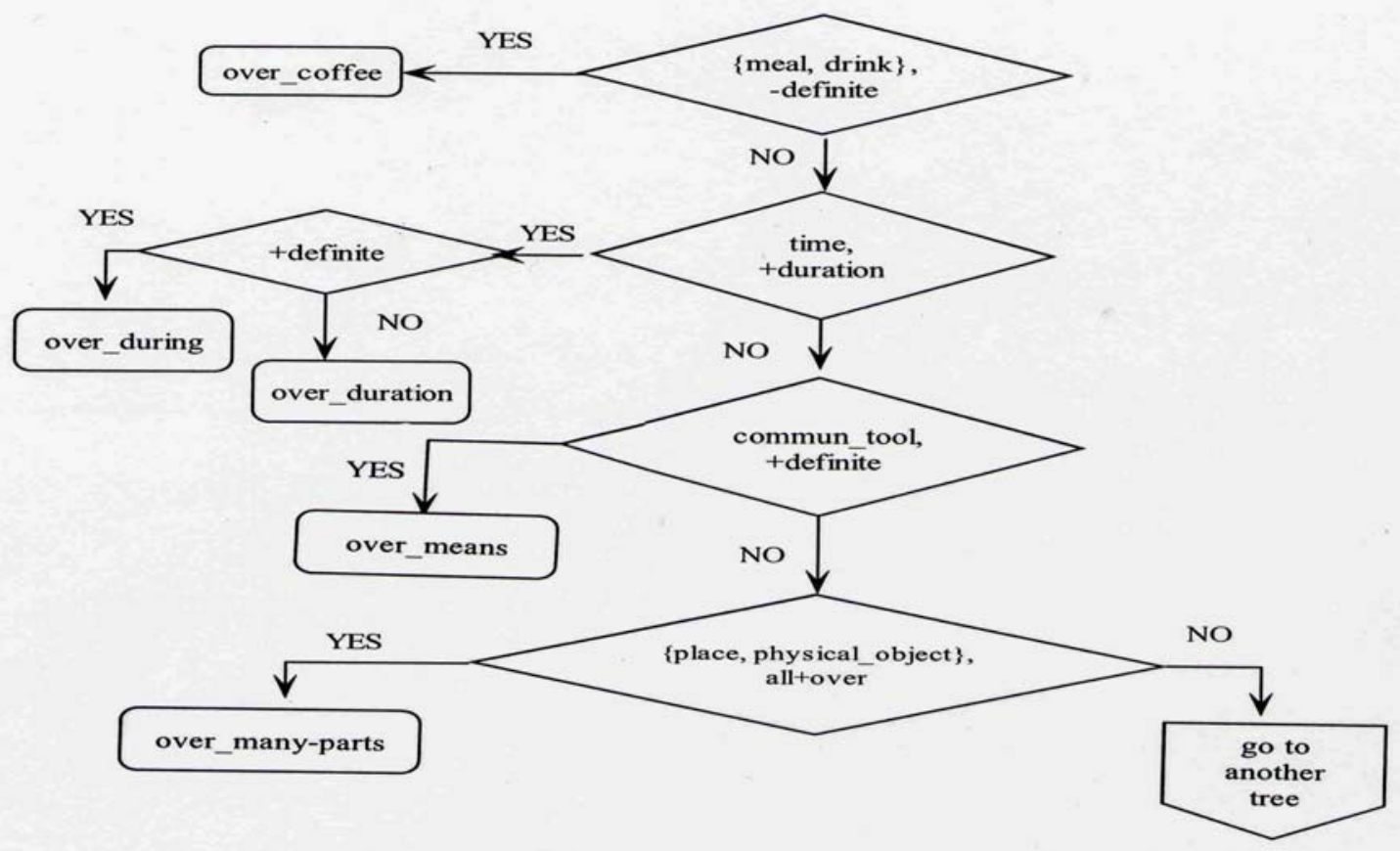

Figure 1. Decision tree for the prepositional uses of over identifiable by the Complements

DOES THE HEAD REFER TO AND/OR CONTAIN ... ?

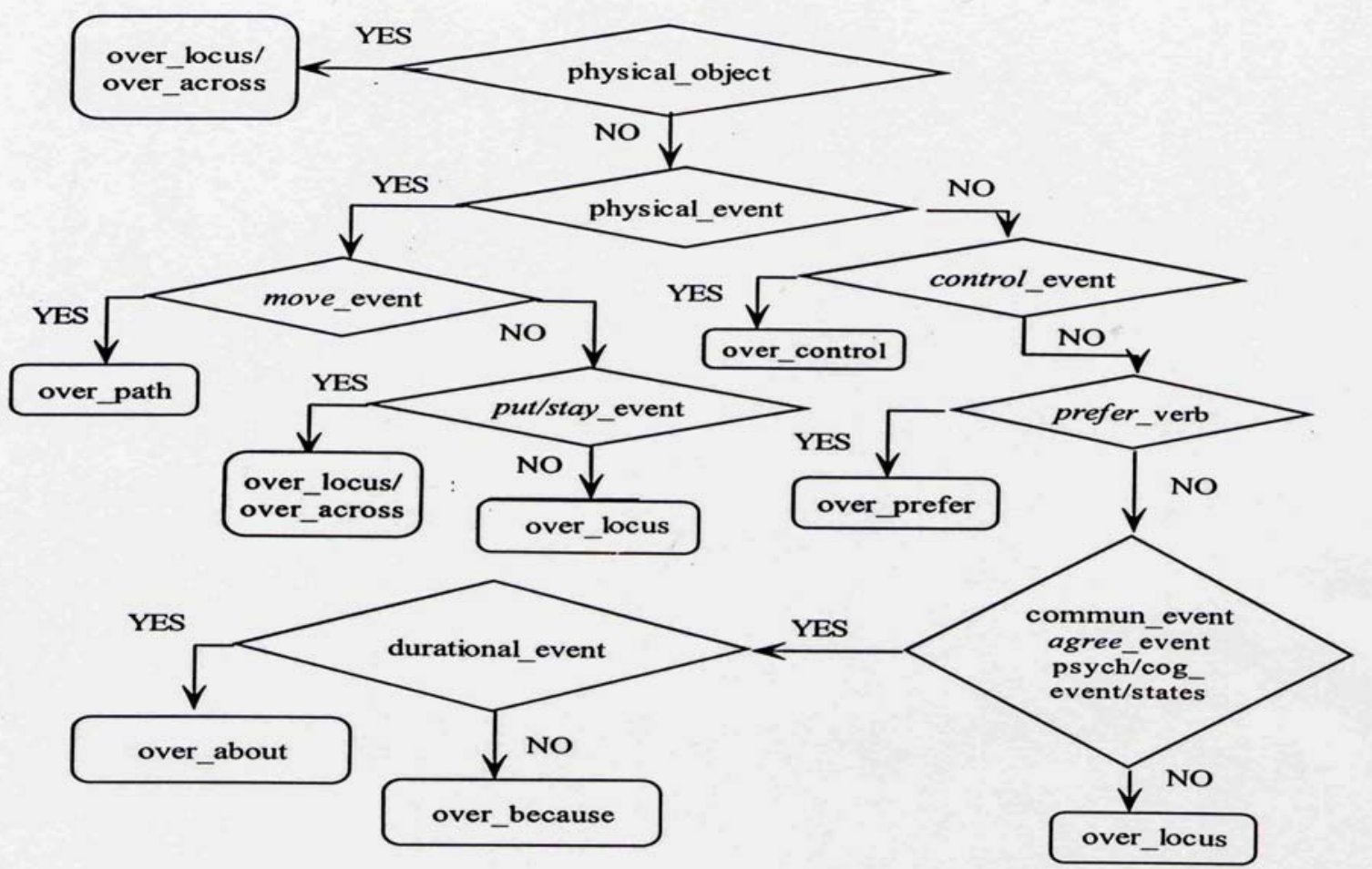

Figure 2. Decision tree for the prepositional uses of over identifiable by the Heads 